\title{
Effect of the extraction conditions of virgin olive oil on the lipoxygenase cascade: Chemical and sensory implications
}

\author{
By María T. Morales (1), Franca Angerosa (2) and Ramón Aparicio (1) * \\ (1) Instituto de la Grasa. Avda. Padre García Tejero 4, 41012 Sevilla, Spain. \\ (2) Istituto Sperimentale per la Elaiotecnica, 65013 Cittá S. Angelo, Pescara, Italy.
}

\section{RESUMEN}

Efecto de las condiciones de extracción del aceite de oliva virgen en la ruta de la lipoxigenasa: Implicaciones químicas y sensoriales.

Los compuestos volátiles producidos a través de la ruta de la lipoxigenasa son los responsables de los atributos sensoriales más importantes del aceite de oliva virgen. El presente trabajo estudia la evolución de estos compuestos según diferentes condiciones de temperatura y tiempo del proceso de extracción. Se ha determinado la influencia de estos parámetros en la producción de compuestos volátiles $\mathrm{C}_{6}$ y $\mathrm{C}_{5}$ así como el efecto que tienen estos compuestos en los descriptores sensoriales más destacados del aceite de oliva virgen (verde, amargo-picante, dulce e indeseable). Se dan valores óptimos de tiempo y temperatura para la producción de aceites de oliva vírgenes de alta calidad sensorial. Los atributos sensoriales de tres variedades, la española Picual y las italianas Frantoio y Coratina, fueron evaluados y los compuestos volátiles cuantificados mediante dos metodologías diferentes con el fin de evitar que los resultados pudieran circunscribirse a una variedad específica o a un único método de cuantificación.

PALABRAS-CLAVE: Aceite de oliva virgen - Compuestos volátiles - Lipoxigenasa (ruta) - Sistemas de extracción.

\section{SUMMARY}

Effect of the extraction conditions of virgin olive oil on the lipoxygenase cascade: Chemical and sensory implications.

The volatile compounds produced through the lipoxygenase cascade are responsible for the most remarkable sensory attributes of virgin olive oil. The paper analyses the evolution of these compounds according to different conditions of temperature and time of the malaxing process. The influence of these parameters on the production of $\mathrm{C}_{6}$ and $\mathrm{C}_{5}$ volatile compounds is stated together with the effect that the amount of these compounds has on the most remarkable virgin olive oil sensory descriptors (green, bitter-pungent, sweet and undesirable). Optima values of temperature and time are given for producing high sensory quality virgin olive oils. Three cultivars, Spanish Picual and Italian Frantoio and Coratina, were characterised by sensory attributes and volatile compounds quantified by two different methodologies in order to avoid that results could be circumscribed to a specific cultivar or a quantification method.

KEY-WORDS: Extraction systems - Lipoxygenase (cascade) Virgin olive oil - Volatile compounds.

\section{INTRODUCTION}

Virgin olive oil is the oil extracted from the fruit of the olive tree, Olea europea L. This vegetable oil is consumed without a further refining process so retaining volatiles and other minor compounds that give rise to a fragrant and delicate flavour that has been appreciated by consumers since ancient times.

In previous works (Aparicio et al., 1994; Aparicio and Morales 1995) different sensory notes responsible for virgin olive oil flavour were established through the consumer appreciation, the most remarkable being green, sweet, fruity, ripe fruit, ripe olives, undesirable and bitter-pungent. Most of these sensory perceptions are produced by volatile compounds (Flath et al., 1973; Gutiérrez et al., 1975; Solinas et al., 1988; Morales et al., 1995; Aparicio et al., 1996b, Angerosa et al., 1996). From all of them, the green sensory perception is of great importance because the fragrant flavour of the virgin olive oil is produced by the balance between green and fruity notes (Morales et al., 1996). It has been stated that aliphatic $\mathrm{C}_{6}$ compounds and the corresponding hexyl esters (Guth and Grosch, 1991; Guth and Grosch, 1993; Morales et al., 1996) are the main contributors to the "unripe» component of the fruit flavour. Moreover, almost all volatiles responsible for green sensory notes are the major components of the virgin olive oil headspace (Salinas et al., 1987; Morales et al., 1994; Di Giovacchino et al., 1996; Angerosa et al., 1997).

These compounds are biosynthesised from $\mathrm{C}_{18}$-unsaturated fatily acids in plants following the lipoxygenase (LOX) pathway (Vick and Zimmerman, 1987; Hatanaka et al., 1987). This pathway involves the actuation of different enzymes giving rise to different amounts of aldehydes, alcohols and esters having all of them sensory properties and so contributing to the overall flavour. In the case of olive fruits, it has been demonstrated (AIR, 1994) that the LOX pathway promotes the formation of $\mathrm{C}_{6}$ volatile compounds against $\mathrm{C}_{9}$ volatile compounds and, in consequence, a great amount of those volatile compounds responsible for green sensory notes 
(Morales et al., 1996) can be found in fresh and high quality virgin olive oils.

On the other hand, tentative previous studies (Giovacchino and Serraiocco, 1995; Ranalli and Serraiocco, 1996; Ranalli and Angerosa, 1996) have demonstrated that the conditions of the malaxing process during olive oil extraction affect to the sensory quality of virgin olive oil. Thus, the most important goal of this research is to establish an index related to the best extraction conditions through the information of volatile compounds responsible for the unique sensory attributes of virgin olive oil (Aparicio et al., 1996b).

This paper emphasises the importance of temperature and time during the malaxing process on the production of $\mathrm{C}_{5}$ and $\mathrm{C}_{6}$ volatile compounds. Different methodologies and varieties have been used to avoid that results could be circumscribed to a specific cultivar or quantification method.

\section{MATERIALS AND METHODS}

\section{Samples}

Olive fruits from three different European cultivars -Picual (Spain), Coratina and Frantoio (Italy)- were used in this study. Virgin olive oil was properly obtained from fresh, healthy fruits of good quality collected at early green stage of ripeness that corresponds to value 2 according to the scale suggested by Frias et al., (1993). The extraction of the oil samples was carried out at analytical scale using experimental oil mills. Temperature and time of malaxing were the parameters studied. Different temperature values were selected, the minimum being $25^{\circ} \mathrm{C}$ that corresponds to the "cold» extraction conditions while the maximum $35^{\circ} \mathrm{C}$ is in the neighbour of the maximum suggested by experts (Humanes, 1993). Five malaxing times $(15,30,45,60,90 \mathrm{~min})$ were selected in order to cover the range of time habitually used to extract the oils from the different types of olives selected. Thirty virgin olive oil samples were characterised by their volatile content using dynamic headspace procedures and sensory descriptors.

Another experiment was carried out with intact and cut olive fruits in order to detect if the LOX pathway is induced when olive fruits are damaged (Galliard, 1980). Twenty grams of intact fruits were analysed following the methodology described below (DHS using Tenax TA traps). Cut olives were obtained placing twenty grams of intact fruits in the extraction vessel and cutting five times the pulp of each fruit. Cut olives were analysed immediately they were cut using the same methodology.

\section{Dynamic headspace-Gas Chromatography}

Volatile compounds of virgin olive oil cv. Picual were analysed by a dynamic headspace technique previously reported (Morales et al., 1994; Aparicio and Morales, 1994). Samples of $0.5 \mathrm{~g}$ were heated at $40^{\circ} \mathrm{C}$ and swept with $\mathrm{N}_{2}(200 \mathrm{ml} / \mathrm{min})$ for $15 \mathrm{~min}$ and the volatiles adsorbed on to a Tenax TA trap (Chrompack, Middleburg, The Netherlands) at room temperature. A Chrompack thermal desorption cold trap injector (TCT) was employed to carry out the thermal desorption of the trapped volatiles by heating at $220^{\circ} \mathrm{C}$ for $5 \mathrm{~min}$. The volatiles were then condensed on to a fused silica trap cooled at $-110^{\circ} \mathrm{C}$ with liquid nitrogen for $5 \mathrm{~min}$ just before injection that was carried out by flash heating of the cold trap at $170^{\circ} \mathrm{C}$ where it was held for $5 \mathrm{~min}$. The volatiles were transferred on to a fused silica J\&W (Folsom, CA) DB-WAX column $(60 \mathrm{~m} \times 0.25 \mathrm{~mm}$ i.d., $0.25 \mu \mathrm{m}$ film thickness). The oven temperature was held at $40^{\circ} \mathrm{C}$ for $6 \mathrm{~min}$ and programmed to rise at $2^{\circ} \mathrm{C} / \mathrm{min}$ to a final temperature of $200^{\circ} \mathrm{C}$ where it was held for 10 min. A Hewlett-Packard 5890 series II with a FID detector was employed. Quantification was carried out using isobutyl acetate as internal standard.

The identification of volatile compounds was carried out by MS using identical conditions to Gas Chromatography. A Fisons Mass Detector MD800 coupled to a GC 8000 series was employed. Masslab v1.3 was the software used. Sample components were verified by comparison of mass spectral data with those of authentic reference compounds.

Volatile compounds of virgin olive oil cv. Coratina and Frantoio were analysed by a dynamic headspaceHRGC technique previously developed (Angerosa et al., 1990). Fifty grams of oil was put into a $120 \mathrm{ml}$ Drechsel gas washing bottle with a porous distributor to which was added a known amount of nonan-1-ol (internal standard). Volatiles were stripped with nitrogen $\left(1.2 \mathrm{dm}^{3} / \mathrm{min}\right.$, at $\left.37^{\circ} \mathrm{C}\right)$ for $2 \mathrm{~h}$, trapped on $50 \mathrm{mg}$ of activated charcoal, and eluted with $1 \mathrm{~mL}$ of diethyl ether.

All solvents, for organic residual analysis, were purchased from J.T. Baker (Deventer, Holland); nonan-1-ol (internal standard) from Aldrich (Steinheim, Germany); activated charcoal (0.5-0.85 $\mathrm{mm} ; 20-35$ mesh ASTM) from E. Merck (Schuchardt, Germany). Charcoal was cleaned by treatment in a soxhlet apparatus with diethyl ether and tested before the analyses.

Gas chromatography was carried out with a Carlo Erba Mega Series 5160 fitted with a Nordion silica capillary Carbowax $20 \mathrm{M}$ column (50 m length; 0.32 $\mathrm{mm}$ i.d.; $0.5 \mathrm{~mm}$ film thickness), and equipped with an on-column injection system, a $\mathrm{CO}_{2}$ cryogenic accessory to hold the oven at $25^{\circ} \mathrm{C}$ and a Flame Ionization Detector (FID). The oven temperature program was the following: isotherm at $25^{\circ} \mathrm{C}$ for $7 \mathrm{~min}$, 
from 25 to $33^{\circ} \mathrm{C}$ at $0.8^{\circ} \mathrm{C} / \mathrm{min}$, from 33 to $80^{\circ} \mathrm{C}$ at $2.4^{\circ} \mathrm{C} / \mathrm{min}$ and from 80 to $155^{\circ} \mathrm{C}$ at $3.7^{\circ} \mathrm{C} / \mathrm{min}$; final isotherm at $155^{\circ} \mathrm{C}$ for 20 minutes. The temperature of the detector was held at $240^{\circ} \mathrm{C}$; carrier gas was $\mathrm{H}_{2}$ at $30 \mathrm{kPa}$. Injection volume was $0.5 \mu \mathrm{L}$. The identification of volatile compounds was carried out by MS under identical conditions for GC but now using a Hewlett-Packard Mass Detector coupled to a GC $5890 \mathrm{~A}$ model was used. Sample compounds were identified by comparison of mass spectral data with those of authentic reference compounds and by their retention times.

The authors have pointed out in previous studies that there is a good correlation between the techniques just described above (Morales and Aparicio, 1993).

\section{Sensory properties of volatile compounds}

Assessors: The sensory properties of volatile compounds (odour and taste) were evaluated by five assessors two with more than ten years experience and three who were habitual consumers of virgin olive oil.

HRGC-olfactometry: To assess the aroma notes corresponding to olive oil volatile compounds, an High Resolution Gas Chromatography (HRGC)-olfactometry technique was applied to virgin olive oil samples (Morales et al., 1994). The effluent of the GC column was splitted 1 to 10 to the detector and the sniffing port, respectively. The descriptions of the odouractive regions of the eluate were noted on a form with a pre-printed time scale, assessors did not see the chromatogram. Assessors basically agreed on the odours of volatiles, although different semantic terms where used to describe some of them. A consensus-building discussion was held with assessors to decide the final sensory descriptors.

Threshold values and Tasting of pure compounds: Odour threshold values of volatile compounds, in a matrix of deodorised sunflower oil, were determined by the authors using the method described by Guth and Grosch (1993).

The assessors also carried out the smelling and tasting, in duplicate, at room temperature of four pure volatile compounds that previously had been characterised as responsible for sensory perceptions other than green: hexan-1-ol (Merck, Darmstadt, Germany), (E)-2-hexenal, (E)-2-hexen-1-ol and (E)-3-hexen-1-ol (Aldrich, Milwaukee, Wisconsin, USA). In fact, Aparicio et al., (1996b) found that (E)-2-hexen-1-ol, (E)-3-hexen-1-ol and hexan-1-ol were better characterised by the global sensory perception of undesirable. This characterisation agrees with Bedoukian (1971) who found that the trans forms of hexenols are characterised by a fatty sensory perception while the cis forms are sharp and green.
The volatile compounds were previously diluted in water or paraffin oil, depending on their solubility, to the same approximate concentration as found in virgin olive oil samples.

\section{Panel test}

The sensory evaluation of olive oil is regulated inside The European Union $(\mathrm{EC}, 1995)$. The descriptors of the official panel were set up for describing the most remarkable sensory perceptions for virgin olive oil and not to differentiate subtle changes in the "green" perception. In order to dissect and describe different flavour sensations associated with green perception, eight full trained Italian assessors were requested to evaluate some oils obtained from unripe fruits of different varieties. In all other aspects, it was strictly followed the regulation of the European Union (EC, 1995).

Assessors chose freely their own descriptors by means of associations of the sensations perceived with own former experiences. The descriptors with enough agreement between assessors were selected for the profile sheet (Table I). These sensory descriptors basically agreed with those describing the "green" aroma perception, by either habitual or potential consumers (Aparicio et al., 1994; Aparicio and Morales, 1995), although some other descriptors, mostly related to tasting (bitter and pungent), were also selected for describing the "green" profile of virgin olive oil.

Table I

Sensory descriptors evaluated in virgin olive oil samples (cv. Coratina. Picual and Frantoio). Structured scale from 0 to 5

\begin{tabular}{lccc}
\hline \multicolumn{1}{c}{ Sensory descriptors } & Coratina & Picual & Frantoio \\
\hline Cut green lawn & 0.7 & 1.0 & 1.0 \\
Green leaf or twig & 1.5 & 0.8 & 1.0 \\
Green olives & 2.0 & 1.8 & 2.0 \\
Wild flowers & - & 0.1 & 0.2 \\
Green banana & 0.1 & 0.2 & 0.2 \\
Green tomato & 0.6 & 0.8 & 0.7 \\
Almond & 0.1 & 0.6 & 0.3 \\
Artichoke & 0.7 & 0.3 & 0.6 \\
Apple & - & 0.1 & 0.1 \\
Walnut husk & 1.1 & 0.5 & 1.1 \\
Green hay & - & 0.1 & 0.1 \\
Bitter & 2.8 & 1.8 & 2.1 \\
Pungent & 2.5 & 1.9 & 2.0 \\
\hline
\end{tabular}




\section{Statistical Analysis}

STATISTICA (Statsoft, 1995) was the statistical package employed. Response surfaces were used to plot the fitted model of the selected chemical compounds in a surface along with their observed values in the experiments at different time and temperature during the extraction process. A quadratic smoothing algorithm was applied to the standardised values of each volatile compound.

Canonical Correlation (Tabachnick and Fidell, 1983) was applied for assessing the relationship between sensory attributes and volatiles. This algorithm allows investigating the redundancies between both set of data.

\section{RESULTS AND DISCUSSION}

The sensory evaluation of samples by different descriptors allowed knowing whether they were basically characterised by green attributes. The results of the sensory profiles showed that varieties were characterised by different perceptions of green sensory attribute. Oil from Picual olives is usually characterised by high values of attributes fruity (tomato) and pungent (Aparicio et al., 1994, 1996a, 1997) while this panel test (Table I) characterised the Spanish variety as green olives, green tomato and cut green lawn.

Coratina oil is habitually characterised by the tasting attributes bitter and pungent (Aparicio et al., 1994; McEwan, 1994) but, concerning the green perception, the descriptors were green olives, green leaf or twig and walnut husk (Table I). High intensities of green, fruity and pungent attributes characterised Frantoio oils (FLAIR, 1991) but focusing on green perceptions this oil shows high values of attributes green olives and cut green lawn (Table I).

From the large database of volatiles identified in virgin olive oil (Morales et al., 1994) only a few are responsible for green perceptions (Aparicio et al., 1996b). These volatile compounds are produced through LOX pathway and they are usually known as "green volatile compounds". In this pathway the production of the volatiles is associated to cell damage (Galliard, 1980). Figure 1 clearly shows the differences between two chromatograms corresponding to volatiles produced in intact olives and cut olive fruits $\mathrm{cv}$. Picual. It is noteworthy the main presence of hydrocarbons in intact fruits and the absence of volatile compounds responsible for the final virgin olive oil aroma, only traces of hexanal and hexan-1-ol -both coming from linoleic acid- could be detected. The volatile profile of cut olives shows a considerable change due to the production of green volatile compounds, coming from both linoleic and linolenic acids. Other volatile compounds usually present in the virgin olive oil headspace were also produced after cutting the olives. This experiment states that volatiles are produced, through the lipoxygenase pathway, as soon as olives are cut or damaged.
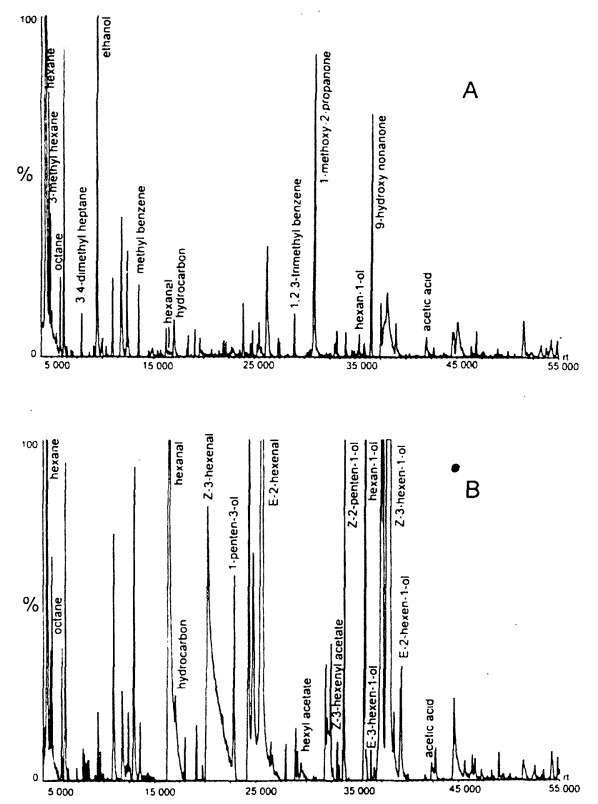

Figure 1

Production of some volatile compounds in intact $(A)$ and cut $(B)$ olives. Quantification by dynamic headspace

Table II shows the $\mathrm{C}_{6}$ volatile compounds analysed in samples. The HRGC-olfactometry showed green sensory notes covering the range between sweet-fruity-green to bitter-powerful-green. The odour threshold and odour activity value (OAV) (Grosch, 1994) are also given. A volatile compound with an OAV greater than 1.0 contributes to the green sensory perception, while volatiles having lesser OAVs could contribute to virgin olive oil flavour through possible synergism phenomena.

Table II

Sensory description, odour thresholds and odour activity values of the green volatile compounds

\begin{tabular}{llcr}
\hline \multicolumn{1}{c}{ Volatile Compounds } & \multicolumn{1}{c}{ Odor descriptors } & Odor thresholds ${ }^{\mathrm{a}}$ & OAV $^{\mathrm{b}}$ \\
\hline Hexanal & Green, apple, green fruit & 60 & 8.91 \\
(Z)-3-hexenal & Green, cut grass & 3.0 & 184.67 \\
(E)-2-hexenal & Green, fruity, almonds & 1200 & 9.76 \\
Hexyl acetate & Fruity, sweet & 1040 & 0.04 \\
(Z)-3-hexenyl acetate & Fruity, green leaves & 730 & 0.07 \\
Hexan-1-ol & Fruit, banana, soft & 400 & 0.13 \\
(E)-3-hexen-1-ol & Green & 1500 & 0.01 \\
(Z)-3-hexen-1-ol & Grass, banana & 5800 & 0.07 \\
(E)-2-hexen-1-ol & Green, grassy, sweet & 8000 & 0.01 \\
\hline
\end{tabular}

Legend: ${ }^{a}$ Calculated in $\mu \mathrm{g} / \mathrm{kg}$

${ }^{\mathrm{b}} \mathrm{OAV}=$ odour activity value. 
The high value of the canonical correlation coefficient $(\mathrm{R}=0.98)$ between the $\mathrm{C}_{6}$ green volatile compounds (Table II) and the sensory attributes (Table I) demonstrates that the former are responsible for the latter. However, the volatiles only explained $66 \%$ of the sensory attributes (redundancies between data sets) and this could mean that the whole information of green sensory attributes is not only explained by the odour of the volatiles but also by the tasting of some of these volatiles as assessors evaluated the samples by their olfactory-gustatory-tactile notes (EC, 1995).

Previous studies using SSW (Aparicio et al., 1994, 1996b) demonstrated that some of these compounds mainly contribute to the green sensory perception i.e. (Z)-3-hexenal, hexyl acetate, (Z)-3-hexenyl acetate, and (Z)-3-hexen-1-ol. However, other set of them could also contribute to other sensory perceptions i.e. (E)-2-hexenal, hexan-1-ol, (E)-3-hexen-1-ol, and (E)-2-hexen-1-ol. The tasting of the latter volatiles allowed their characterisation as astringent and bitter ((E)-2-hexen-1-ol and (E)-3-hexen-1-ol), rough (hexan-1-ol) and sharp, bitter, astringent ((E)-2-hexenal).

There is good agreement among consumers in relation to the sensory perceptions. They dislike high intensities of tasting perceptions bitter and pungent, while they like almost all aroma descriptors qualified with the adjective green (McEwan, 1994; Pagliarini et al., 1994). Therefore, the presence of volatiles responsible for pleasant sensory perceptions should be promoted. However virgin olive oil must be extracted solely using physical means, and then the ratio between volatiles in the final product can only be varied by changing the temperature and time of the malaxing process. Depending on temperature and time of malaxing, each volatile compound showed different behaviour.

Figure 2 shows a scheme of the LOX pathway with its three different branches for the production of volatiles. The branch coming from linoleic acid give rise to hexanal, hexan-1-ol and hexyl acetate, being the former and the latter responsible of desirable perceptions. This branch could be seen as the green-sweet aspect of the global green flavour. The second branch could be seen as the responsible of the main green perception, being constituted by (Z)-3-hexenal, (Z)-3-hexenol and (Z)-3-hexenyl acetate. The third branch giving rise to $(\mathrm{E})-2$-hexenal and (E)-2-hexen-1-ol could be considered as the bitter-astringent aspect of the green sensory perceptions.
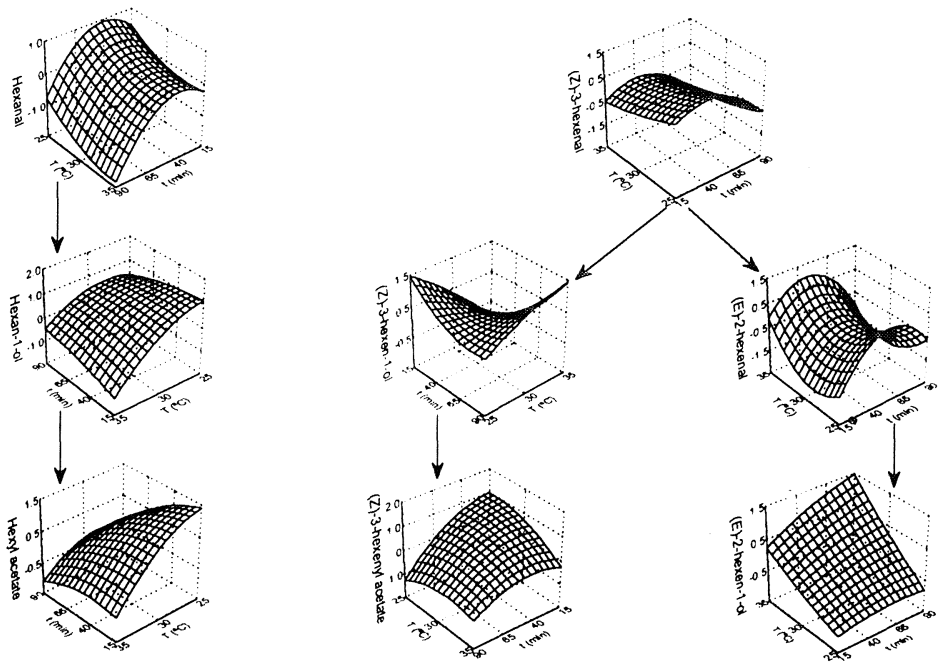

Figure 2

Response surfaces of $\mathrm{C}_{6}$ volatile compounds produced through the lipoxygenase cascade. The surface has been fitted to the data by a $2^{\text {nd }}$ order polynomial function and volatile compounds were previously normalised by Z-score. The figures of volatile compounds have been rotated (clokwise or counter-clokwise) in order to expose the results better.

Hexanal, responsible for green, apple, sweet perceptions, has an OAV $=8.91$ (Table II), therefore contributing to pleasant sensory perceptions. The production of hexanal is more influenced by the time of malaxing than by the temperature, hexanal is produced during the whole process but the highest concentrations were found after 45 minutes of malaxing. A different behaviour showed volatile
(E)-2-hexen-1-ol that is characterised by a green smelling and an astringent-bitter tasting, the latter being an undesirable sensory perception for potential consumers (McEwan, 1994). The production of (E)-2-hexen-1-ol is mainly affected by temperature since the highest concentrations were measured at the highest temperature of malaxing $\left(35^{\circ} \mathrm{C}\right)$. Hexyl acetate is also affected by temperature but, in this 
case, the highest concentration of this ester was measured at the lowest temperature $\left(25^{\circ} \mathrm{C}\right)$.

The other compounds responsible for green aroma descriptors ((Z)-3-hexenal, (Z)-3-hexen-1-ol, and (Z)-3-hexenyl acetate) also showed the higher concentrations at low temperature, Figure 2. The influence of malaxing time was low for (Z)-3-hexenal, medium for (Z)-3-hexen-1-ol and higher for (Z)-3-hexenyl acetate. This means that the production of (Z)-3-hexenal is almost immediate while the production of (Z)-3-hexenyl acetate needs more time. This explanation agrees with the sequence of production of these volatiles through the LOX pathway. The first step of this biochemical pathway is the formation of the aldehyde, then its transformation to alcohol -by the action of alcohol dehydrogenase enzyme (ADH)- and later the formation of the ester, by means of the alcohol acyl transferase enzyme (AAT). It is noteworthy that (Z)-3-hexen-1-ol is represented by a sharp saddle picture. It has two maximum peaks -at low temperature and low time and at high temperature and high time- so suggesting that the latter condition (high temperature and high time of malaxing) makes easier the formation of this compound in detriment of (Z)-3-hexenyl acetate while the former conditions enables its transformation on (Z)-3-hexenyl acetate, both being characterised as green volatiles.

Concerning the volatiles responsible for the undesirable sensory perceptions ((E)-2-hexenal, hexan-1-ol, (E)-3-hexen-1-ol), their concentrations are higher when the temperature of the malaxing is the highest, Figure 2. In this case, the time of malaxing had no influence on the formation of the alcohols but it showed a great influence on the formation of the aldehyde. The concentration of the aldehyde was lower at high and low malaxing times and higher at medium values of time for the Picual variety though certain differences were found from the results of Coratina and Frantoio varieties. The intermediate volatile compound (E)-2-hexenal is represented by a typical saddle picture where, once again, there are two maximum peaks at low and high temperatures under medium time of malaxing. According to the sensory characterisation of (E)-2-hexenal and (E)-2-hexen-1-ol the low temperature gives the bitter tasting to virgin olive oil but when temperature reaches high values than this sensory perception in virgin olive oil is accompanied by an undesirable perception that can make the oil to be rejected.

In general, the highest concentrations of aldehydes were measured when the time of malaxing was shorter, the production of alcohols was promoted at high temperature $\left(35^{\circ} \mathrm{C}\right)$ and the concentration of esters was higher at low temperature $\left(25^{\circ} \mathrm{C}\right)$. This means that the malaxing process at high temperature $\left(T \geq 35^{\circ} \mathrm{C}\right.$ ) promote the formation of green volatiles responsible for undesirable sensory perceptions while, on the contrary, low temperatures $\left(T \geq 25^{\circ} \mathrm{C}\right)$ favoured the production of desirable green sensory perceptions. The temperature is then the main factor characterising the malaxing process.

Recently Angerosa et al., (1998) have suggested a branch of the lipoxygenase cascade for $C_{5}$ volatile compounds. An alkoxy radical would be produced from 13-hydroperoxide by the action of the lipoxygenase, later by $\beta$-scission would produce 1,3-pentene radical and an unsaturated aldehyde. A series of pentene dimers would be produced by dimerization of 1,3-pentene while the hydroxilation would produce 2-penten-1-ol and 1-penten-3-ol that will then produce 1-penten-3-one and 2-pentenal by the action of the alcohol dehydrogenase. $\mathrm{C}_{5}$ volatile compounds have a sensory behaviour quite similar to $\mathrm{C}_{6}$ volatile compounds, there are contributors to green, (Z)-2-penten-1-ol and (E)-2-pentenal, sweet, 1-penten-3-one, pungent, 1-penten-3-ol, and undesirable, (Z)-2-pentenal and 1-penten-3-ol, sensory perceptions (Aparicio et al., 1996b).

(Z)-2-penten-1-ol, responsible for green banana, is promoted at low values of temperature $\left(25^{\circ} \mathrm{C}\right)$ and time $(15 \mathrm{~min})$ while its lowest values are at the highest values of these variables, so showing a similar behaviour to $\mathrm{C}_{6}$ volatile compounds responsible for green perceptions, Figure 3 . The next volatile in this lipoxygenase cascade, 1-penten-3-ol, has its highest values immediately the malaxing begins and its concentration diminishes when malaxing goes on time; the temperature seems to have poor influence on its production, Figure 3 . This behaviour can be interpreted as these compounds are produced in parallel process and the production of these volatile compounds begins immediately the olives are crushed; these compounds already appeared in the chromatogram of cut olives, Figure 1. (Z)-2-pentenal is produced from the previous compounds and Figure 3 shows that the volatile reaches its optimum after a certain delay; in fact, it does appears at trace levels in Figure 1. The production of 1-penten-3-one is increased with temperature, so suggesting it is produced through an oxidation process. Figure 3 shows that its maximum is reached with a delay similar to that of (Z)-2-pentenal.

The main conclusion of the present study is that low temperature $\left(T \geq 25^{\circ} \mathrm{C}\right)$ and medium times (35-45 min.) are the best extraction conditions to promote the formation of green volatile compounds responsible for desirable sensory perceptions. High temperature $\left(T \geq 35^{\circ} \mathrm{C}\right)$ with minimum values of time $(t<35 \mathrm{~min}$.) could also be useful as a alternative way to obtain pleasant green virgin olive oils. 

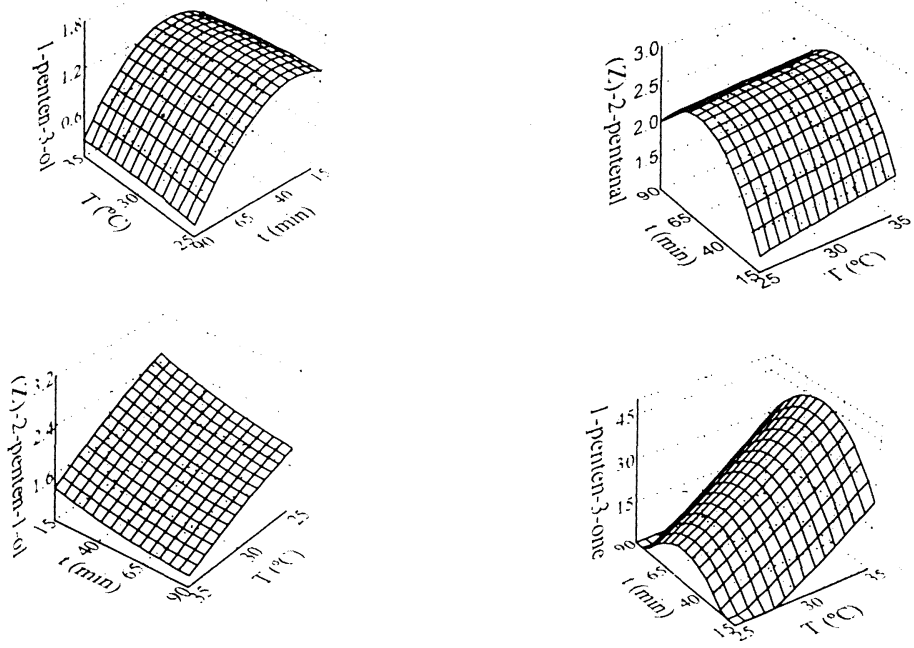

Figure 3

Response surfaces of $C_{5}$ volatile compounds at different temperatures and times of malaxing. The surface has been fitted to the data by a $2^{\text {nd }}$ order polynomial function. Values of volatile compounds are given in $10^{*} \mathrm{ppm}$.

All the results, coming from either volatile compounds or sensory attributes information, point out that low temperature during malaxing (an industrial example is percolation) is determinant to obtain pleasant green virgin olive oils in any of the studied varieties.

\section{ACKNOWLEDGEMENTS}

The authors would like to acknowledge their indebtedness to assessors who carried out the sensory evaluation of the samples. This work has been supported by AIR3-CT94-1967.

\section{BIBLIOGRAPHY}

AIR (1994).—«European Project AIR3-CT94-1967. Olive oil flavour and aroma: biochemistry and chemistry of sensory factors affecting consumer appreciation and their analysis by artificial intelligence, The Commission of the European Communities".

Angerosa, F., Di Giacinto, L. and Solinas, M. (1990)."Influence of olive fruit mass storage on the aroma of resulting oils. Evaluation of "fusty" defect by HPLC and GLC analyses of volatile compounds".-Riv. Merceol., 29, 275-294.

Angerosa, F., Di Giacinto, L., Vito, R. and Cumitini, S. (1996)."Sensory evaluation of virgin olive oils by artificial neural network processing of dynamic head-space gas chromatographic data".-J. Sci. Food Agric., 72, 323-328.

Angerosa, F., Di Giacinto, L. and D'Alessandro, N. (1997)."Quantitation of some flavor components responsible for the "green" attributes in virgin olive oils".-J. High Resol. Chromatogr., 20, 507-510.

Angerosa, F., Camera, L., d'Alessandro, N. and Mellerio, G. (1998).- "Characterization of seven new hydrocarbons compounds present in the aroma of virgin olive oils".-J. Agric. Food Chem., 46, 648-653.
Aparicio, R. and Morales, M.T. (1994).- «Optimization of a dynamic headspace technique for quantifying virgin olive oil volatiles. Relationships among sensory attributes and volatile peaks".-Food Qual. and Pref., 5, 109-114.

Aparicio, R. and Morales, M.T. (1995).— «Sensory wheels: a statistical technique for comparing QDA panels. Application to virgin olive oil».-J. Sci. Food Agric., 67, 247-257.

Aparicio, R., Alonso, M.V., Morales, M.T. and Calvente, J.J. (1994)._- «Relationship between COI test and other sensory profiles by statistical procedures".-Grasas Aceites, 45, 26-41.

Aparicio, R., Calvente, J.J. and Morales, M.T. (1996a)."Sensory authentication of European extra-virgin olive oil varieties by mathematical procedures".-J. Sci. Food Agric., 72, 435-447.

Aparicio, R., Morales, M.T. and Alonso, V. (1996b)."Relationship between volatile compounds and sensory attributes of olive oils by the sensory wheel».-J. Am. Oil Chem. Soc., 73, 1253-1264.

Aparicio, R., Morales, M.T. and Alonso, V. (1997)."Authentication of European extra-virgin olive oils by their chemical compounds, sensory attributes and consumers attitudes".-J. Agric. Food Chem., 45, 1076-1083.

Bedoukian, P.Z. (1971).- - The seven primary hexenols and their olfactory characteristics".-J. Agric. Food Chem., 19, 1111-1114.

Di Giovacchino, L., Angerosa, F. and Di Giacinto, L. (1996)._- Effect of mixing leaves with olives on organoleptic quality of oil obtained by centrifugation".J. Am. Oil Chem Soc., 73, 371-374.

Di Giovacchino, L. and Serraiocco, A. (1995)._«Influenza dei sistemi di lavorazione delle olive sulla composizioni dello spazio di testa degli oli».-Riv. Ital. Sostanze Grasse, 72, 443-450.

EC. (1995).--Official Journal of The Commission of The European Communities. March 28th, 3-4 Regulation n. ${ }^{1}$ 656/95.

FLAIR (1991).-European Project FLAIR-CT91-0046, The study of sensory and nutritional quality of virgin olive oil in relation to variety, ripeness and extraction technology, The Commission of the European Communities. First Year Report. 
Flath, R.A., Forrey, R.R. and Guadagni, D.G. (1973)."Aroma components of olive oil».-J. Agric. Food Chem, 21, 948-952.

Frías, L., García-Ortiz, A., Hermoso, M., Jiménez, A., Llavero, M.P., Morales, J., Ruano, M.T. and Uceda, M. (1993).--Analistas de Laboratorio de Almazara, Andalusian Ministry of Agriculture, Seville (Spain).

Galliard, T. (1980).- The Biochemistry of Plants, Vol. 4, Academic Press, London.

Grosch, W.(1994).- —Determination of potent odourants in foods by aroma extract dilution analysis (AEDA) and calculation of odour activity values (OAVs)".-Flavour Fragr. J., 9, 147-158.

Guth, H. and Grosch, W. (1991).- «A comparative study of the potent odorants of different virgin olive oils".-Fat. Sci. Technol., 93, 335-339.

Guth, H. and Grosch, W. (1993)._- QQuantitation of potent odorants of virgin olive oil by stableisotope dilution assays".-J. Am. Oil Chem. Soc., 70, 513-518.

Gutiérrez, R., Olías, J.M., Gutiérrez, F., Cabrera, J. and del Barrio, A. (1975). - «The chromatographic and organoleptic methods in the evaluation of the aromatic characteristics of virgin olive oil".-Grasas y Aceites, 26, 21-31.

Hatanaka, A., Kajiwara, T. and Sekiya, J. (1987).«Biosynthetic pathway for $\mathrm{C}_{6}$-aldehydes formation from linolenic acid in green leaves».-Chem. Phys. Lipids, 44, 341-361.

Humanes, J. (1993).-Producción de Aceite de Oliva de Calidad: Influencia del cultivo, Junta de Andalucía, Consejería de Agricultura y Pesca, Seville (Spain).

McEwan, J. A. (1994).— «Consumer attitudes and olive oil acceptance: the potential consumer".-Grasas $y$ Aceites, 45, 9-15.

Morales, M.T. and Aparicio, R. (1993).- «Optimization by mathematical procedures of two dynamic headspace techniques for quantifying virgin olive oil volatiles".-Anal. Chim. Acta, 282, 423-431.

Morales, M.T., Aparicio, R. and Ríos, J.J. (1994)."Dynamic headspace gas chromatographic method for determining volatiles in virgin olive oil».-J. Chromatogr. A, 668, 455-462.
Morales, M.T., Calvente, J.J. and Aparicio, R. (1996)."Influence of olive ripeness on the concentration of green aroma compounds in virgin olive oil».-Flavour Fragr. J., 11, 171-178.

Morales, M.T., Alonso, M.V., Ríos, J.J. and Aparicio, R. (1995).«Virgin olive oil aroma: relationship between volatile compounds and sensory attributes by chemometrics".J. Agric. Food Chem., 43, 2925-2931.

Pagliarini, E., Bertuccioli, M. and Abba, S. (1994)."Consumer attitudes and olive oil acceptance: the traditional consumer".-Grasas y Aceites, 45, 16-19.

Ranalli, A. and Angerosa, F. (1996).- «Integral centrifuges for olive oil extraction. The qualitative characteristics of products".-J. Am Oil Chem. Soc., 73, 417-422.

Ranalli, A. and Serraiocco, A. (1996).- «Evaluation of characteristics of olive oil produced by innovative and traditional processing technologies".-Riv. Ital. Sostanze Grasse, 73, 303-315.

Solinas, M., Angerosa, F. and Marsilio, V. (1988).- Indagine su alcuni componenti dell'aroma degli oli vergini di oliva in relazione alla varietà delle olive».-Riv. Ital. Sostanze Grasse, 45, 361-368.

Solinas, M., Marsilio, V. and Angerosa, F. (1987). — «Evoluzione di alcuni componenti dell'aroma degli oli vergini di oliva in relazione al grado di maturazione delle olive».-Riv. Ital. Sostanze Grasse, 44, 475-480.

Statsoft, (1995).--STATISTICA release 5, Tulsa, USA.

Tabachnick, B.G. and Fidell, L.S. (1983).-Using Multivariate Statistics, Happer and Row Publishers, New York.

Vick, B.A. and Zimmerman, D.C.(1987).-«Oxidative systems for modification of fatty acids: the lipoxygenase pathway".-In The Biochemistry of Plants: A Comprehensive Treatise, Vol. 9, p. 53.

Stumpf, P.K. and E.E. Conn, (Eds.).-Academic Press Inc., New York.
Recibido: Junio 1998 Aceptado: Septiembre 1998 